\title{
SOBRE EL SIGNIFICADO DEL SILENCIO DEL BUDDHA
}

\author{
ENRIQUE BOCARDO \\ Universidad de Sevilla \\ Visiting Scholar, Wolfson College (Cambridge) \\ Fulbright Visiting Scholar, Harvard University
}

\begin{abstract}
RESUMEN. El objetivo principal del ensayo es intentar entender el significado del silencio del Buddha ante las diez proposiciones sin declarar. Si se consideran como dițthi, las preguntas sin declarar son simplemente un conjunto de proposiciones conceptualmente distorsionadas. El trabajo se ha dividido en cinco secciones. En las dos primeras se presenta la explicación del Buddha de su propio silencio. Tienen un alcance meramente expositivo con el objeto de situar la discusión en los términos en que fue originariamente planteada. La tercera parte explica los mecanismos mentales que intervienen en la generación mental de patrones mentales distorsionados. El papel que desempeña papañca en el desarrollo de las tendencias subyacentes y la aparición de efluvios mentales se ha desarrollado en la cuarta parte. Finalmente, se presenta el silencio del Buddha como la respuesta que es consistente con el conjunto de principios doctrinales que él mismo declaró.
\end{abstract}

PALABRAS CLAVE: las diez cuestiones sin declarar; el silencio del Buddha; concepciones distorsionadas; generación mental (papañca); tendencias subyacentes; engaños y efluvios mentales.

\section{About the meaning of the Buddha's silence}

ABSTRACT. The main purpose of the paper is to try to understand the Buddha's silence as a proper answer to the ten unanswered question set. When regarded as ditțhi, the undeclared questions are meant to be considered as a set of conceptually distorted propositions. The paper is divided into five sections. The first two sections deal with the Buddha's own explanation of his silence. Its scope is mainly expository and aims to place the discussion in context. The third part is devoted to explain the mental mechanisms involved in generating conceptually distorted mental patterns. A detailed analysis of the cognitive mechanisms related to papañca has been given in order to clarify the meaning of both mental defilements and the notion of inflowing in the fourth section. Finally, the explanation of the Buddha's silence is presented as an answer consistent with set of publicly avowed principles he professed

KEY WORDS: the ten undeclared questions; the Buddha's silence; distorted conceptions; mental generation (papañca); latent dispositions; mental defilements; inflowing.

\section{Namo tassa Bhagavato Arahato Sammāsambuddhassa}

En un número de pasajes de los Suttantas al Buddha se le formulan ciertas preguntas que, a pesar de la iluminación ( sammāsambudha) que le permite una penetración absoluta en la comprensión de los fenómenos físicos y mentales (ñana y dassana), deja, ante la

* [Este trabajo ha surgido en el marco del proyecto de investigación cuatrianual «Historia Conceptual y Crítica de la Modernidad» (FFI2017-82195-P) del Ministerio de Ciencia, Innovación y Universidades del Gobierno de España]. 
sorpresa de sus interlocutores, sin responder ${ }^{1}$. Al parecer, se trataba de preguntas comúnmente entendidas como un desafío intelectual- que se les hacía a los dirigentes de las diferentes escuelas filosóficas (samanâa), y que podrían haber servido para evaluar el alcance teórico de cada posición, en función de la agudeza mental que exhibía el maestro cuando aceptaba el desafío de responderlas ${ }^{2}$.

En la literatura budista, esas preguntas se conocen tradicionalmente como avyākata no decididas, o no resueltas. Preguntas que el Buddha ha dejado con su silencio, indeterminadas, sin responder, o cuyas posibles soluciones se han dejado a un lado, o han sido meramente descartadas (thapaniya).

El conjunto lo forman tradicionalmente diez preguntas dividas en tres grupos ${ }^{4}$. El primer grupo incluye preguntas sobre la naturaleza del universo:

1) El universo es eterno ( sassato loko)

2) El universo no es eterno (asassato loko)

3) El universo es finito (antavā loko)

4) El universo no es finito (anantavā loko)

El segundo grupo contiene preguntas relativas a la relación entre mente y cuerpo:

5) El alma y el cuerpo son lo mismo (tam jīvaṁ tami sarīrami)

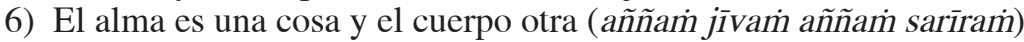

Y finalmente, el tercer grupo lo forman preguntas relativas a la naturaleza del Tathāgata, es decir, sobre la naturaleza de aquellos que han logrado la completa iluminación alcanzando un estado de conocimiento que los sitúa más allá de la percepción ordinaria de la realidad ${ }^{5}$ :

7) Si el Tathāgata existe después de la muerte (hoti tathāgato param, maraṇa

8) Si el Tathāgata no existe después de la muerte (na hoti tathāgato param, marañā)

9) Si el Tathāgata existe y no existe después de la muerte (hoti ca na ca hoti tathāgato param, maraṇā)

1 En Majjhima Nikāyai 63 y 72. y los once Avyakata Suttas contenidos en Samyutta Nikāya,44, 1-11; Udāna 6.4 y 6.5. También se pueden encontrar referencias a las diez preguntas en Dīgha Nikāya 1,$1 ; 6,16-19 ; 9,25 ; 29$. Todas las citas de los textos del Pāli Canon, salvo indicación previa, se refieren a la edición del Sexto Concilio Budhista (CSCD).

2 Ver especialmente Samyutta Nikāya iv, 398.

3 En sánscrito el término «avyākata», significa literalmente «no respondidas», o «no contestadas».

Panikkar habla de «catorce posiciones» en lugar de diez. La diferencia consiste en que en la enumeración de los posiciones añade cuatro nuevos enunciados, que sin embargo no se recogen en los suttas:

3. El mundo es y no es temporalmente infinito.

4. El mundo ni es ni no es temporalmente infinito.

5. El mundo es y no es espacialmente infinito.

6. El mundo ni es ni no es espacialmente infinito.

R. Panikkar, El silencio del Buddha, Ediciones Siruela, Madrid, 1996, 135 y 137-8.

5 K. R. Norman, 'Death and the Tathāgata', Studies in Buddhism and Culture (in honour of Prof. Egaku Mayeda), Tokyo, 1991, 252-63. 
10) Si el Tathāgata ni existe y ni deja de existir después de la muerte (n'eva hoti na na hoti hoti tathāgato param, marañā).

En términos lógicos, las preguntas que se formulan en (1)-(10), comprenden cinco pares de proposiciones que incluyen una proposición y su contraria. De hecho, los pares de las proposiciones (1)-(2), (3)-(4), (5)-(6), (7)-(8) respectivamente, son de la forma $(\mathrm{X} v \sim \mathrm{X})$; mientras que la estructura del par (9)-(10) es de la forma $(\mathrm{X} \& \sim \mathrm{X})$ y $\sim(\mathrm{X} \&$ $\sim \mathrm{X})$, respectivamente. Los enunciados (1)-(10) son perfectamente gramaticales, así que las proposiciones que expresan deberían de estar sujetas, en principio, a los criterios de decisión lógica en cuyos términos se establece el valor de verdad de una proposición. Asumiendo el principio del tercio excluso, cada proposición contenida en los cinco pares de proposiciones (1)-(10) afirma $(\mathrm{X} \vee \sim \mathrm{X})$, o $(\mathrm{X} \& \sim \mathrm{X})$ o su negación $\sim(\mathrm{X} \& \sim \mathrm{X})$, sería razonable asumir que al menos una de las dos, $\mathrm{X}$ o $\sim \mathrm{X}$ debe ser verdadera; lo que eventualmente obligaría al Buddha a decidirse o bien por bien por la verdad de $\mathrm{X}$, o por la verdad de $\sim \mathrm{X}$, o bien que declare como una contradicción la proposición «X \& $\sim \mathrm{X}$ ».

El Buddha, sin embargo, ni se decide por el valor de verdad de $\mathrm{X}$ ni por el valor de verdad de $\sim X$, pero tampoco declara $\sim(X \vee \sim X)$, lo que implicaría la contradicción de afirmar al mismo tiempo una proposición y su contraria, afirmando como contradictoria la conjunción de $\mathrm{X}$ y de $\sim \mathrm{X}$.

La perplejidad ante el silencio del Buddha descansa en la asunción de que el Buddha deja sin resolver las preguntas (1)-(10), que hubiera podido responder, aceptada la presuposición de que su mente habría tenido acceso absoluto al conocimiento de la realidad; lo que no significa necesariamente presuponer que la mente del Buddha fuera omnisciente. Bajo esta asunción, se han defendido básicamente dos líneas de interpretación. Una, que el Buddha las deja sin resolver porque no estaba interesado en cuestiones metafísicas tan abstractas y complejas ${ }^{6}$. Y la otra, que las deja sin responder porque la respuesta a esas cuestiones no afectan al problema central del sufrimiento humano, y en ese caso, el Buddha habría pensado que era mejor dejarlas sin resolver ante el temor de que sus respuestas podría desviar a sus seguidores del camino que conduce a la liberación ${ }^{7}$.

En uno y otro caso, la línea de interpretación asume que el valor de los enunciados de las preguntas (1)-(10) son de alguna manera decidibles, pero que es un asunto que no afecta al conjunto de problemas que el budismo se propone resolver, pero insiste en que las preguntas que el Buddha deja sin resolver se podrían responder y por consiguiente las proposiciones que expresan podrían ser cognoscibles.

Esta línea de interpretación está sujeta a un número de objeciones fatales. Si bien es cierto que hay una sólida evidencia para considerar las proposiciones (1)-(10) como ajenas a las preocupaciones del budismo por resolver el problema del sufrimiento; y que el Buddha las rechaza abiertamente porque ninguna de ellas conduce al nibbānami, no es menos cierto, sin embargo, que no sólo hay evidencia textual en los Suttantas para pensar que no puedan ser decidibles o no decidibles, sino que las razones que da el Buddha para explicar el silencio como respuesta, indican que las proposiciones

6 T. Vetter, The ideas and meditative practices of Early Buddhism, E. J. Brill, Leiden, 1988, 41-3. R. Gethin, The foundations of Buddhism, Universtiy Press, Oxford 1998, 67. Gethin, se refiere al libro de Vetter, pero omite las referencias al año y a las páginas del libro de Vetter.

Samyutta Nikāya v, 437-8. Citado en R. Gethin, ob. cit. 67. 
(1)-(10) son el resultado de un profunda ilusión mental, y, en consecuencia, su silencio aparece como la única respuesta consistente con los principios que el Buddha ha declarado explícitamente. Ni el Buddha, ni la mente de una arahant, pueden entrar en la cuestión de si los enunciados (1)-(10) son, o no son decidibles; la decibilidad sobre esos enunciados simplemente no surge en la mente de aquél que ha erradicado los mecanismos que generan los patrones simbólicos de representación en cuyos términos se formulan esas preguntas.

En lo que sigue intentaré explicar qué significa entender los enunciados (1)-(10) como ditthi (concepciones distorsionadas). La elucidación de esta cuestión es decisiva para entender el significado del silencio como respuesta. Primero porque proporciona los mecanismos cognitivos en cuyos términos se explica la habilidad de la mente de crear patrones subjetivos de representación. Segundo, porque el examen de estos mecanismos nos remite a entender tres factores mentales cruciales en la creación de ilusiones mentales: los mecanismos mentales responsables de la actividad de papañca, el papel que desempeñan las tendencias subyacentes (anusaya $\vec{a}$ como mecanismos inconscientes que refuerzan los patrones subjetivos de representación y la acción de los efluvios mentales (āsava) en la consolidación de mental de las concepciones distorsionadas. Y por último, porque la compresión de estos mecanismos cognitivos determina la diferencia entre el estado mental de una persona común (puriso) y el estado mental de un arahant. De hecho, extinción de las tendencias subyacentes y de los efluvios mentales en la mente del arahant explican por qué el silencio es la única respuesta que el Buddha podría haber dado para responder las preguntas que plantean los enunciados (1)-(10).

\section{I}

Guardar silencio en lugar de responder, es, de acuerdo al Canon, una manera de contestar a la pregunta que se hace. En los Suttantas se reconoce cuatro maneras diferentes de responder a una pregunta:

«Estas son las cuatro maneras de responder a las preguntas. Cuáles son esas cuatro maneras? Hay preguntas que se tendrían que responder de manera categórica (directamente con un «sí, o con un «no», diciendo «esto, o «eso». Hay preguntas que se deberían de responder con explicaciones (definiendo o redefiniendo los términos en los que se formulan). Hay otras preguntas que se deberían de responder con un pregunta contraria. Hay preguntas que se deberían de dejar a un lado. Estas son las cuatro maneras de responder a las preguntas $»^{8}$.

Así que cuando el Buddha decide dejar sin responder las preguntas (1)-(10), está, de hecho, respondiendo a esas preguntas; por consiguiente, su silencio se ha de entender como una respuesta a los enunciados (1)-(10). De hecho, el mismo Buddha explica por qué responde con el silencio a esas preguntas:

\section{Pañha Sutta en Añguttara Nikāya iv, 42:}

«Cattārimāni bhikkhave pañhavyākaraṇāni. Katamāni cattāri:

Atthi bhikkhave pañho ekaṃsavyākaraṇīyo, atthi bhikkhave pañho vibhajja vyākaraṇīyo, atithi bhikkhave pañho pațipucchā vyākaraṇiyo, atthi bhikkhave pañho țhapanīyo. Imāni kho bhikkhave cattāri pañhavyākaraṇānīti».

Véase asimismo Majjhima Nikāya i, 72 y Anguttara Nikāya: 3. 67; 3. 78; 5. 165 y 10. 96. 
«Todas las proposiciones (1)-(10), Vacha, son una espesura de concepciones distorsionadas, un apegarse a las concepciones distorsionadas, una jungla de concepciones distorsionadas, un retorcimiento de concepciones distorsionadas, un crisparse ante las concepciones distorsionadas, una atadura a las concepciones distorsionadas. Conducen al sufrimiento, a lo que causa irritación, a la aflicción, a la excitación (fiebre); no conducen a la disipación de la ilusión [mental], ni a la serenidad, ni a la cesación, ni a la paz, ni al conocimiento intuitivo, ni al despertarse por uno mismo, ni tampoco al nibbānaṁ»? .

En este texto el Buddha presenta dos clases de razones para explicar su silencio. En la primera enumera una sucesión de ciertos estados mentales que son descritos en términos metafóricos como dițthigatametam் («espesura»), dițthikantāro («jungla») dițhivisūkaṁ («retorcimiento»). El uso de esos términos parecen sugerir que la formulación de los enunciados (1)-(10) son la consecuencia de un profundo estado ilusorio de conciencia, que impide al que formula las preguntas reconocer que las proposiciones de la forma $(\mathrm{X} v \sim \mathrm{X})$ y su negación son el resultado de una distorsión conceptual, o expresan una clase de sin sentido, y, en consecuencia, no está en condiciones de percatarse que los enunciados (1)-(10) no están sujetos a los criterios habituales que se emplean para decidir el valor de verdad. La indecisión que expresa el silencio descansa en el reconocimiento de que el estado mental responsable de la formulación de los enunciados (1)-(10) incapacita al que las formula a que se percate que se encuentra bajo el efecto de una ilusión mental. La idea es que las ilusiones mentales no pueden curarse con una discusión que promueva la generación de otros estados mentales igualmente ilusorios.

El silencio del Buddha ante las preguntas que formulan los enunciados (1)(10), sugeriría que la naturaleza de la ilusión mental que eventualmente permite la formulación de esas preguntas es demasiado profunda, o que está muy enmarañada, o que debido a la insondable confusión mental que presenta, es simplemente inescrutable, o demasiado retorcida, como parece aludir la expresiones dițhigatametam, ditthikantāro ditthivisūkam. Cualquier intento por desenmarañar la compleja red de opiniones distorsionadas con argumentos racionales estaría condenado al fracaso, porque no conducirían al que sostiene cualquiera de esas opiniones a que se percatara de que no tiene sentido preguntarse si alguna de las opiniones contenidas en (1)-(10) son verdaderas o son falsas. El mero intento de verse obligado a preguntar por su valor de verdad es el síntoma de una profunda ilusión mental. La terapia se hace aún más difícil si se tiene en cuenta que, además de representar un honda distorsión conceptual, son opiniones con las que el sujeto mantiene un vinculo emocional. El uso de los términos dițhigahanam, o ditthivipphanditam, parecen sugerir que la masa de opiniones distorsionadas que representan las proposiciones (1)-(10) estén relacionados con procesos emocionales con los que tiende a identificarse quien las sostiene.

9 Majjhima Nikāya i, 486:

«'asassato loko' ti kho, vaccha ... pe ... 'antavā loko' ti kho, vaccha ... pe ... 'hoti ca na ca hoti tathāgato param maranāa' ti kho, vaccha ... pe ... 'neva hoti na na hoti tathāgato param maraṇā' ti kho, vaccha dițhigatametạ̣ dițhigahanam diț̣ikantāro diț̣ivisūkam diț̣hivipphanditạ̣ diț̣isaṃyojanaṃ sadukkhạ̣ savighātaṃ saupāyāsạ̣ saparịāhaṃ, na nibbidāya na virāgāya na nirodhāya na upasamāya na abhiññāya na sambodhāya na nibbānāya saṃvattati». 
La segunda clase de razones que ofrece el Buddha para rechazar responder a las preguntas (1)-(10), probablemente expresen la deliberada intención de remarcar la diferencia esencial entre el enfoque distintivamente budista y las especulaciones características de otras escuelas contemporáneas. En esencia, lo que viene a expresar la segunda clase de razones es que las concepciones distorsionadas que expresan las preguntas (1)-(10) no sólo no solucionan el problema esencial de la existencia humana: la liberación de la muerte y el sufrimiento, sino que además causan más dolor y miseria.

De hecho, presenta las preguntas (1)-(10) como un conjunto de especulaciones filosóficas esencialmente contrarias a la correcta visión de la realidad (sammā ditthi) enunciada en el principio de condicionalidad (paticca-samuppāda), que constituye una de las escasas reivindicaciones del Buddha sobre su conocimiento ${ }^{10}$, y sobre el que en última estancia se basa la doctrina específicamente budista de las cuatro verdades nobles (cattāri-ariyasaccāni).

Probablemente el enunciado más antiguo del principio de condicionalidad se encuentre en el Vinayapitakam:

«A continuación, el Baghava en la primera vigilia de la noche dirigió su mente hacia el principio de condicionalidad (literalmente a la relación que explica que todo lo que surge depende de algo) tanto en dirección directa como en dirección inversa: de la ignorancia como condición [surgen] las formaciones kármicas; de las formaciones kármicas como condición, la conciencia; de la conciencia como condición, la mente y la materia; de la mente y la materia como condición, las seis bases de la percepción ${ }^{11}$, de las seis bases de la percepción, el contacto; del contacto como condición, el sentimiento; del sentimiento como condición, la avidez; de la avidez como condición, el apego; del apego como condición, la existencia; de la existencia como condición, el nacimiento; del nacimiento como condición, la vejez y la muerte, así se originan las tribulaciones del dolor, el lamentarse y los estados de ánimos desagradables de la mente y el cuerpo. Tal es, pues, el origen de toda esta masa de sufrimiento» ${ }^{12}$.

El principio de paticca-samuppāda expresa el conocimiento último de la realidad que libera del sufrimiento, cuando la realidad es vista como una secuencia de la acción de doce factores (angāni) en la que cada factor es condicionado por el anterior, según el principio genérico «Cuando X se da, Y se da; con el surgimiento de X, Y también surge» (imasmim sati idam hoti, imass' uppada idam uppajati). En esencia, es una explicación de todos lo fenómenos en términos de estados condicionantes (paccayadhammâ),

10 Véase especialmente Vinayapitakam: Mahāvagga, i, 22-26.

11 El término «salāyatanā», literalmente (sala-āyatanāa) «la seis bases», a menudo también traducidas como «esferas», se refiere a la estructura física (rūpa) que comprende cada uno de los cinco órganos sensoriales; respectivamente: ojo (cakkhu), oído (sota), nariz (ghāna), lengua (jivhāa), cuerpo ( $k a \bar{a} y a)$, además de la estructura no física, mente (mano) por donde acceden los objetos mentales (dhammā).

12 Vinayapitakaṃ: Mahāvagga, i, 1:

Athakho bhagavā rattiyā pațhamạ̣ yāmam paticcasamuppādam anulomapatilomaṃ manasākāsi avijjāpaccayā sañkhārā sankkhārapaccayā viññannạ̣ viññannapaccayā nāmarūpạ̣ nāmarūpapaccayā saḷāyatanaṃ salāyatanapaccayā phasso phassapaccayā vedanā vedanāpaccayā tạnhā tanhhāpaccayā upādānaṃ upādānapaccayā bhavo bhavapaccayā jāti jātipaccayā jarāmaraṇaṃ sokaparidevadukkhadomanassupāyāsā sambhavanti evametassa kevalassa dukkhakkhandhassa. 
estados condicionados ( paccayuppannadhammā) y la manera en que se relacionan entre si (paccayasatti), y, por consiguiente, exhibe la estructura causal (o condicionante) de la rueda de existencia (vatta) identificando a los doce factores (ignorancia, formaciones kármicas, conciencia, mente y materia, las seis bases de la percepción, contacto, el sentimiento, la avidez, el apego, la existencia, el nacimiento, y la vejez y la muerte), que mantienen a todos los seres vivos dando vueltas una y otra vez en los interminables ciclos de existencias (samisāra).

Todos los fenómenos que comprenden la existencia son condicionados, de manera que su aparición y eventual desaparición, depende solo de la presencia o de la ausencia de los factores que condicionan su presencia. Toda forma de vida, sea cual sea el plano de la existencia en la que aparezca, es el resultado de un conjunto de condiciones, que son las que invariablemente causan al final el sufrimiento. En este esquema explicativo, no es posible identificar una sola causa como la única causa del sufrimiento. Las vueltas de las existencias pasadas condicionan la aparición de la ignorancia y de las formaciones kármicas, la avidez, el apego y la existencia. La existencia presente, por su parte, está condicionada por la aparición de la conciencia, la mente y la materia, las seis bases sensoriales, el contacto y el sentimiento, que por su parte, condicionan los procesos de avidez y apego, mientras dura la vida presente. Finalmente, las vueltas de las futuras existencias, que aparecen como el resultado kármico de la existencia presente, dan lugar inevitablemente al nacimiento (la aparición de una forma de vida en un plano particular de la existencia), a la vejez y a la muerte ${ }^{13}$.

El primer factor, ignorancia (avijjā), está condicionado por las consecuencias de las acciones pasadas, y junto con la avidez y el apego, se entienden como las condiciones que mantienen a la conciencia en un continuo proceso de engaño mental (kilesâa), que impide percatarse de la estructura causal que condiciona la aparición de la masa de sufrimiento. En esencia, ignorancia significa simplemente ausencia del conocimiento de las cuatro verdades, que el Buddha las enunció en los siguientes términos:

«Esta es, en verdad, la verdad noble del sufrimiento: el nacimiento es sufrimiento, la vejez es sufrimiento, la enfermedad es sufrimiento, la muerte es sufrimiento, relacionarse con las personas que no queremos es sufrimiento, separase de las personas que queremos es sufrimiento, no conseguir lo que uno quiere es sufrimiento, en resumen, el apego a los cinco agregados es sufrimiento ${ }^{14}$.

También existe, bhikkhus, la verdad noble sobre el origen sufrimiento, esta avidez que nos mantiene en la existencia, que conduce al siguiente nacimiento, que acompaña al placer y a la concupiscencia, que encuentra su gozo aquí y allí, esa persistente avidez por los placeres, esa continua avidez por mantenerse en la existencia, y esa continua avidez por no existir.

13 Abhidhammatthasangaha:: A Comprehensive Manual of Abhidhamma. Editado by Bhikkhu Bodhi. Kandy, Buddhist Publication Society, 1999, 301-2.

14 El Budha se refiere a los cinco agregados «pañcakkhandhā», literalmente los cinco componentes que dan forma, por así decirlo, a la existencia: el cuerpo, los sentimientos, las percepciones sensoriales, las voliciones, y la conciencia, y que inevitablemente conducen a la ilusión de concebir la entidad personal como un yo, o ego, que es el sujeto que subyace detrás de los procesos físicos, emocionales y epistemológicos que desarrollan respectivamente cada uno de los agregados. 
Esta es, bhikkhus, la verdad noble de la cesación del sufrimiento: la completa ausencia de pasión, la destrucción, el abandono, la liberación, la eliminación de esta avidez.

Esta es, bhikkhus, la verdad noble del camino que conduce a la cesación del sufrimiento: el camino que se compone de ocho partes intrínsecas, que son; una visión correcta, un propósito (intención) correcta, una manera de hablar correcta, una conducta correcta, una forma de ganarse la vida correcta, un esfuerzo correcto, una atención correcta y una concentración correcta» ${ }^{15}$.

En la epistemología budista se acostumbra a distinguir entre dos tipos irreducibles de realidades. De una parte, la realidad convencional (sammuti-saccâ), se trata de la realidad que se construye mentalmente (parikappana) y en cuya elaboración intervienen el uso de conceptos, y los patrones habituales de representación simbólica incorporados en las gramáticas del lenguaje ${ }^{16}$. El Buddha rechaza explícitamente el conocimiento convencional como:

«una necedad, una estupidez, sin la completa comprensión, engañoso, desconcertante, lleno de ilusión, (basado) en la ignorancia, atrapado en la corriente de la ignorancia, sujeto a la ignorancia, (intoxicado) por las disposiciones latentes de la mente de la ignorancia, dominado por la ignorancia, entorpecido por la ignorancia, ofuscado por la raíz de la conducta inmoral» ${ }^{17}$.

La otra realidad es la realidad última (paramattha-sacca $\vec{a}$, cuya existencia es enteramente independiente de la capacidad simbólica que tiene el lenguaje para conceptualizar la realidad, y que es accesible sólo cuando se abandonan los medios convencionales para entender la realidad gracias a la inmersión de profundos estados de absorción meditativa que se conocen como jhānā y en los que la realidad se ve realmente como es (yathābhūtami), a través de:

«ser consciente, de la comprensión, la realización, del despertar, de la inmersión, de la penetración, de la sumersión, de la visión, de la contemplación, de la percepción directa» ${ }^{18}$.

Cuando el Buddha reclama que el que camino medio (majjhimā patipadā) que él mismo ha descubierto, tiene la capacidad de producir literalmente: «la visión clara, la

15 Vinayapitakam: Mahāvagga, i, 12-15.

«Idam kho pana bhikkhave, dukkhạ̣ ariyasaccaṃ: jātiṢpi dukkhā. JarāṢpi dukkhā, vyādhiṢpi dukkhā. Maraṇampi dukkham, appiyehi sampayogo dukkho. Piyehi vippayogo dukkho, yampiccham na labhati, tampi dukkham. Sankkhittena pañcupādānakkhandhā dukkhā»».

«Idam kho pana bhikkhave dukkhasamudayam ariyasaccam: yāyam tạhā ponobhavikā nandirāgasahagatā tatra tatrābhīnandanī, yeyyathīdaṃ: kāmataṇhā bhavataṇhā vibhavataṇhā».

«Idam kho pana bhikkhave dukkhanirodham ariyasaccaṃ: yo tassāyeva taṇhāya asesavirāganirodho cāgo paṭinissaggo mutti anālayo».

«Idam kho pana bhikkhave, dukkhanirodhagāminī patipadā ariyasaccaṃ: ayameva ariyo aț̣hangiko maggo, seyyathīdaṃ: sammādiț̣hi, sammāsañkappo, sammākammanto, sammāājivo sammāvāyāmo, sammāsati, sammāsamādhi».

16 La evidencia más sustantiva para justificar los mecanismos cognitivos responsables de la construcción mental de la realidad se encuentra en dos textos de Majjhima Nikaya: i, 112 y el más interesante $\mathrm{i}, 118$.

17 Dhammasangaṇī, 196: «dummejjham, bālyaṃ, asampajaññạ̣, moho, pamoho, sammoho, avijjā, avijjogho, avijjāyogo, avijjānusayo, avijjāpariyuṭthānaṃ, avijjālang, moho, akusalamūlaṃ».

18 Dhammasangañī, 196: «dassanam, abhisamayo, anubodho, sambodho, pativedho, saṃāhanā, pariyogāhanā, samapekkhanā, paccavekkhaṇā, and paccakkhakammaṃ» 
comprensión que conduce a la tranquilidad, a la verdadera sabiduría, a la iluminación y al nibbānamì» ${ }^{19}$, está, por una parte reconociendo que la clase de conocimiento que produce la liberación del sufrimiento y de la muerte y que literalmente rompe la cadena de causalidad que mantiene a los seres atados al saṁsāra, no es alcanzable utilizando los mecanismos cognitivos en cuyos términos la realidad convencional es conocida; $\mathrm{y}$, por otra, está asumiendo dos tipos irreducibles de visiones o concepciones: una visión correcta de la realidad (sammāditthi), que es accesible cuando se alcanza los estados de profunda absorción meditativa, y una concepción distorsionada de la realidad (ditthi) que surge como consecuencia de los patrones cognitivos simbólicos de representación, que determinan el conocimiento de la realidad convencional (sammuti-saccāa).

\section{II}

Entendidas como ditthi, las proposiciones (1)-(10) son, en primer lugar, el resultado de la ignorancia (avijjâ). Son la consecuencia de un conjunto de factores (kiles $\vec{a})$ que mantienen a la conciencia en un estado de ilusión mental, responsable de que la cuatro verdades nobles sean inaccesibles al conocimiento directo. En particular, quien se pregunta por la verdad de las proposiciones (1)-(10), se podría decir que se encuentra en estado ilusorio de conciencia que impide:

(i) que se de cuenta de la primera verdad noble, a saber que:

«el nacimiento es sufrimiento, la vejez es sufrimiento, la enfermedad es sufrimiento, la muerte es sufrimiento, relacionarse con las personas que no queremos es sufrimiento, separase de las personas que queremos es sufrimiento, no conseguir lo que uno quiere es sufrimiento, en resumen, el apego a los cinco agregados es sufrimiento».

(ii) Que, como consecuencia de la ignorancia de la primera verdad, no sea consciente que el sufrimiento tiene un origen,

(iii) que no intuya que la avidez es origen del sufrimiento, y que finalmente,

(iv) sea incapaz de percatarse que existe un camino que conduce a la cesación del sufrimiento, que eventualmente disiparía la ilusión mental que le ha llevado a preguntarse si las proposiciones (1)-(10) son o no son verdaderas.

Esta clase de ilusión mental explicaría por qué que el Buddha considera que las preguntas que se plantean en (1)-(10) conduzcan «al sufrimiento, a lo que causa irritación, a la aflicción, a la excitación (fiebre)», y decida responderlas con el silencio.

En segundo lugar, las proposiciones (1)-(10) se formulan en términos de la concepción convencional de la realidad (sammuti-saccā), que el Buddha rechaza enfáticamente como una visión contraria a la visión correcta de la realidad, y en consecuencia, las proposiciones (1)-(10) no producen:

(i) una visión clara,

(ii) ni la comprensión que conduce a la tranquilidad, ni a la verdadera sabiduría, ni a la iluminación ni al nibbānam.

19 Vinayapitakaṃ: Mahāvagga, i, 11.

ayaṃ kho sā bhikkhave, majjhimā paṭipadā tathāgatena abisambuddhā cakkhukarạ̣i ñāṇakaraṇī upasamāya abhīññaya sambodhāya nibbạ̣āya sạ̣vattati 
De ahí que explique su silencio en la segunda clase de razones simplemente porque, las proposiciones (1)-(10) no conducen, «a la disipación de la ilusión [mental], ni a la serenidad, ni a la cesación, ni a la paz, ni al conocimiento intuitivo, ni al despertarse por uno mismo, ni tampoco al nibbānaṁ».

En un conocido pasaje de los Suttantas, el Buddha se sirve de una metáfora extensamente repetida en la literatura secundaria que ilustra especialmente las dos clases de razones para explicar su silencio:

«Malunkyaputta, si alguien fuera a decir, «No seré capaz de llevar una vida bienaventurada bajo el Baghava, a menos que se pronunciara sobre [sigue a continuación los enunciados de las preguntas (1)-(10)], ese hombre habría de morir y todas esas preguntas seguirían sin ser declaradas por el Tathāgata.

Sería como si un hombre Malunkyaputtta, estuviera herido por una flecha que hubiera sido embadurnada con mucho veneno. Después de que sus amigos y compañeros procuraran encontrarle un médico, el hombre, sin embargo, dijera «No habrán de extraerme esta flecha hasta que sepa si el hombre que me hirió era un guerrero noble, o un brahmán, o un comerciante, o un bracero. O que dijera, «No me habrán de extraerme esta flecha hasta que no sepa el nombre y al clan al que pertenece el hombre que me hirió ... o hasta que sepa si era alto, medio o bajo de estatura... o hasta que sepa si el color de su piel era oscuro, castaño o rubio... hasta que sepa la villa, el pueblo o la ciudad en la que nació ... hasta que sepa si el arco con el me hirió era largo o fue con una ballesta, ... hasta que sepa con qué clase de cuerda se hizo el arco con el me hirió, si era de filamentos, o de hilos de bambú, o de ligamento, o de cáñamo, o de tendón, o de corteza.. hasta que sepa si la punta de la flecha que me hirió era silvestre o forjada, ... hasta que sepa si las plumas del emplumando de la flecha que me hirió eran de buitre, o de cigüeña, o de halcón, o de pavo real o de cualquier otra ave ... hasta que sepa si la punta de la flecha que me hirió estaba unida a la barra con el ligamento de un buey, o de un búfalo de agua, o de un langur, o de un mono». Y continuara diciendo: «No habrán de extraerme la flecha hasta que sepa si la punta de la flecha que me hirió se lanzó con un arco común, o curvo, o de púas, o fabricado con dientes de ternera o de adelfa». Seguramente ese hombre habría de morir, y todas aquellas cosas que preguntaba seguirían siendo desconocidas.

De la misma manera, si alguien fuera a decir que no habría de seguir una vida bienaventurada bajo el Baghava hasta que se pronunciara sobre [sigue a continuación los enunciados de las preguntas (1)-(10)], también ése habría de morir, y todas esas cosas seguirían sin ser declaradas por el Tathāgata» ${ }^{20}$.

\section{Majjhima Nikāya i, 63:}

«Yo kho mālunkkyaputta evaṃ vadeyya: na tāvāhaṃ bhagavati brahmacariyạ̣ carissāmi, yāva me bhagavā na byākarissati: ... [sigue a continuación los enunciados de las preguntas (1)-(10)] ... Abyākatameva tạ̣ mālunikyaputta tathāgatena assa.

Atha so puggalo kālạ̣ kareyya, seyyathāpi mālun̉kyaputta puriso sallena viddho assa savisena gāḷapalepanena. Tassa mittāmaccā ñātisālohitā bhisakkạ̣ sallakattaṃ upațhapeyyuṃ, so evaṃ vadeyya: na tāvāhạ̣ imạ̣ sallạ̣ āharissāmi. Yāva na tạ̣ purisạ̣ jānāmi, yenamhi viddho: khattiyo vā brāhmaṇo vā vesso vā suddovāti.

So evạ̣ vadeyya: na tāvāhaṃ imạ̣ sallaṃ āharissāmi. Yāva na tạ̣ purisaṃ jānāmi, yenamhi viddho: evamnāmo evaṃgotto itivāti. 
La metáfora parece haber sido concebida con el fin de ilustrar la ineficacia epistemológica de los enunciados (1)-(10) para resolver la muerte como una condición intrínseca de la existencia humana. Las preguntas que formulan los enunciados (1)-(10) son simplemente inútiles. No son la clase de preguntas que uno debería de plantearse, si quien las formula fuera consciente que inevitablemente va a morir.

El significado simbólico de la metáfora se articula en tres elementos. Primero la situación en la que se encuentra el hombre herido por una flecha envenenada sirve para ilustrar la primera verdad noble (dukkham ariyasaccam), presentando una situación en la que sea relativamente fácil percibir la muerte como una condición necesaria del sufrimiento, y que, sin embargo, pasa completamente desapercibida para alguien que ha sido mortalmente herido.

El segundo elemento resalta, en particular, la ignorancia (avijjâ) como la causa que induce a un estado ilusorio de conciencia: paradójicamente quien es consciente de que ha sido herido por una flecha envenenada, no es, sin embargo, consciente que va a morir. La ignorancia aparece como una ilusión mental que es la responsable de una particular inconsciencia, que le impide al que ha sido herido por la flecha envenenada darse cuenta que va a morir.

El tercer elemento resalta la inutilidad del conocimiento que persigue de las preguntas (1)-(10), presentando la serie de preguntas que hace el hombre herido por la flecha como el resultado de un estado ilusorio de conciencia. Intentar averiguar la casta del hombre que ha lanzado la flecha, o su estatura, o el color de su piel, o el color de su pelo, o su

So evam vadeyya: na tāvāhaṃ imaṃ sallaṃ āharissāmi. Yāva na tạ̣ purisaṃ jānāmi, yenamhi viddho dīgho vā rasso vā majjhimo vāti.

So evaṃ vadeyya: na tāvāhaṃ imạ̣ sallạ̣ āharissāmi yāva na tạ̣ purisạ̣ jānāmi, yenamhi viddho: kālo vā sāmo vā mañguracchavi vāti.

So evạ̣ vadeyya: na tāvāhạ̣ imạ̣ sallaṃ āharissāmi, yāva na tạ̣ purisạ̣ jānāmi, yenamhi viddho: asukasmim gāme vā nigame vā nagare vāti.

So evaṃ vadeyya: na tāvāhạ̣ imaṃ sallạ̣ āharissāmi yāva na tạ̣ dhanuṃ jānāmi, yenamhi viddho: yadi vā cāpo yadivā kodaṇdoti.

So evam vadeyya: na tāvāham imam sallam āharissāmi, yāva na tạ jiyam jānāmi yāyamhi viddho: yadi vā akkassa yadi vā saṇṭhassal yadi vā nahārussa yadi vā maruvāya yadi vā khīrapaṇninoti. So evaṃ vadeyya: na tāvāhaṃ imaṃ sallaṃ āharissāmi. Yāva na tạ̣ kaṇdạ̣ jānāmi. Yenamhi viddho: yadi vā kacchạ̣ yadi vă ropimanti.

So evaṃ vadeyya: na tāvāham imam sallam āharissāmi. Yāva na tạ̣ kaṇụ̣ jānāmi yenamhi viddho: yassa pattehi vājitam, yadi vā gijjhassa yadi vā kankkassa yadi vă kulalassa yadi vā morassa yadi vā sithilahanunoti.

So evaṃ vadeyya: na tāvāham imaṃ sallaṃ āharissāmi. Yāva na tạ̣ kaṇdạ̣ jānāmi. Yenamhi viddho: yassa nahārunā parikkhittạ̣, yadi vā gavassa yadi vā mahisassa yadi vā roruvassa. Yadi vā semhārassāti.

So evaṃ vadeyya: na tāvāhaṃ imaṃ sallạ̣ āharissāmi. Yāva na tạ̣ sallạ̣ jānāmi. Yenamhi viddho: yadi vā sallaṃ yadi vā khurappạ̣ yadi vā vekaṇdạ̣ yadi vā nārācaṃ yadi vā vacchadantạ̣ yadi vā karavīrapattanti. aññātameva tạ̣ māluṇkyaputta tena purisena assa. Atha so puriso kālaṃ kareyya.

Evameva kho māluṇkyaputta yo evaṃ vadeyya: na tāvāham bhagavati brahmacariyạ̣ carissāmi, yāva me bhagavā na byākarissati: [sigue a continuación los enunciados de las preguntas (1)-(10)] ... Abyākatameva tạ̣ māluṇkyaputta tathāgatena assa. Atha so puggalo kālaṃ kareyya. 
procedencia. Saber la clase de arco que utilizó para lanzar la flecha, o la clase de cuerda que se empleó para fabricarlo, y toda la secuencia que sigue, ponen de manifiesto que esa clase de conocimiento resulta ser inútil para extraer la flecha envenenada.

En términos de la realidad convencional, las preguntas que se hace el hombre herido por la flecha son todas ellas perfectamente decidibles: es posible saber la casta del hombre que lanzó la flecha, o su estatura. También es posible averiguar si las plumas eran de halcón o de pavo real, o el material con el que se fabricó la punta de la flecha, o de qué estaba hecha la cuerda del arco. Pero igualmente son todas ellas preguntas irrelevantes, que al final no proporcionan la clase de conocimiento que se necesita para extraer la flecha.

III

Para comprender las razones que da el Budda para explicar su silencio, es necesario identificar los mecanismos cognitivos que inducen a la mente a crear una realidad ilusoria distorsionada por las concepciones (ditthi), lo que eventualmente proporcionaría las razones para explicar los enunciados (1)-(10) en los términos en los que los entiende el propio Buddha, respectivamente como dițthigatametam, dițthigahanam, ditṭikantāro, ditthivisūkam, ditthivipphanditam y finalmente como dițhisamyojanam.

La identificación de los procesos cognitivos aparecen descritos en algunos pasajes del Canon en donde se explica la diferencia entre el estado mental de un persona ordinaria (puriso) y el estado mental del arahant, que ha alcanzado la completa iluminación.

El Madhupindikasuttam comienza con una declaración explícita del Buddha sobre el contenido de su enseñanza, cuando responde a la pregunta kimvādī samaṇo kimakkhāyī» ti (literalmente: «¿qué declara el maestro, qué proclama?»:

«Lo que declaro es esto: que en este mundo no haya disputa con los dioses, Maras y sus Brahmas, que en esta generación tampoco exista entre sus ascetas y sus brahmanes, sus príncipes y sus pueblos, de suerte que las percepciones sensoriales no hagan surgir las disposiciones latentes ${ }^{21}$ en el brahmán que vive desprendido de los de los placeres sensuales, sin incertidumbre, libre de preocupaciones, libre de la apetencia de cualquier clase de ser, tal es, Señor, lo que yo declaro, tal es lo que yo proclamo» ${ }^{22}$.

La respuesta del Buddha sugiere que la enseñanza fundamental de su doctrina consiste en la erradicación de las disputas y conflictos entre seres humanos, si fueran capaces de extinguir todas las tendencias subyacentes que generan las percepciones

21 La traducción de la negación del verbo anusenti, requiere alguna explicación. La raíz del verbo en Sánscrito es anu-śī (śete). El verbo śí significa permanecer o estar sin uso, quedarse dormido, tener relaciones sexuales con el marido, o ser impotente. Los dos últimos significados probablemente indiquen el sentido figurativo de una acción que sea recurrente, o que tiende a repetirse, o que sienta la necesidad de hacerse y que no pueda hacerse. Así que habría razones para traducirlo como la acción de que hay algo que permanece latente, o dormido, o subyacente.

22 Majjhima Nikāyai, 109:

«yathāvādī kho, āvuso, sadevake loke samārake sabrahmake sassamaṇabrāhmaṇiyā pajāya sadevamanussāya na kenaci loke viggayha tiț̣ati, yathā ca pana kāmehi visaṃyuttạ viharantạ̣ tạ̣ brāhmaṇạ̣ akathạ̣kathị̣ chinnakukkuccam bhavābhave vītatạ̣hạ̣ saññā nānusenti — evaṃvādī kho ahạ̣, āvuso, evamakkhāyīti». 
sensoriales, como es capaz de hacerlo quien haya alcanzado la iluminación (arahant). En este pasaje, algo desconcertante para la epistemología occidental, el Buddha identifica, pues, el estado mental del iluminado como aquel en el que las percepciones sensoriales no hagan surgir las disposiciones latentes.

Más adelante el Buddha explica el sentido de lo que quiere decir cuando utiliza la expresión «las percepciones sensoriales no hagan surgir las disposiciones latentes» en los siguientes términos:

«bhikkhu, se debe a que la generación mental (multiplicación) de las distinciones verbales que provienen de las percepciones fluyen en la mente de la persona común. Debido a esto, nada hay que resulte placentero, nada hay que se haya que sostener, nada hay a lo que se haya apegar. Es el fin de las tendencias subyacentes ${ }^{23}$ de la avidez, el fin de las tendencias subyacentes de la irritación, el de las tendencias subyacentes de las opiniones distorsionadas, el fin de las tendencias subyacentes de las vacilaciones [distracciones mentales], el fin de las tendencias subyacentes sobre las concepciones de la identidad de uno mismo, el fin de las tendencias subyacentes de la avidez por la existencia, el fin de las tendencias subyacentes de la ignorancia, el fin de las tendencias subyacentes a echar mano del garrote, de las armas, de los conflictos, de los enfrentamientos, de las disputas y de los reproches, de las calumnias y de las mentiras. En suma, cuando todas las acciones inmorales de la mente cesan, sin dejar tras de sí rastro alguno» ${ }^{24}$.

El Buddha marca una clara distinción entre el estado mental de una persona común (puriso) y el estado mental del arahant, en cuyos términos explica el sentido de la expresión

23 La traducción del término «anusayā» es necesario explicarla. La palabra está etimológicamente relacionada con el verbo anusenti. Parece indicar una inclinación hacia algo o proclividad, o una tendencia a que se repita una determinada acción. No se trata, sin embargo, de la mera repetición de un hábito, sino de una disposición o tendencia mental subyacente, o latente, a que se repita una acción; de ahí que normalmente se traduzca como «tendencias subyacentes» o «disposiciones latentes de la mente». Es posible que se trate simplemente de aspectos no conscientes o subconscientes de la mente, que presumiblemente han surgido como resultado de la persistencia en multiplicar o a generar continuamente los conceptos y palabras sujetos a la identidad personal, que provienen de las percepciones sensoriales en el transcurso de los ciclos de la existencia y que formarían parte de las formaciones kármicas que inducen a la aparición una forma de vida en un determinado plano de la existencia. En la concepción budista, la mente tiene una historia mucho más larga que no está limitada por la vida psicológica de la persona. La mente es el resultado de un largo proceso temporal de los ciclos del samsāra, que resume todas las existencias pasadas, y por consiguiente es el resultado de ciertos patrones mentales que estarían relacionados de alguna manera con las tendencias subconscientes o subyacentes acumuladas de existencias pasadas y que determinan, por así decirlo, la forma particular de pensar con la que nacemos.

24 Majjhima Nikāya, i, 110:

«yatonidānaṃ, bhikkhu, purisạ̣ papañcasaññāsan̉khā samudācaranti. ettha ce natthi abhinanditabbạ̣ abhivaditabbạ̣ ajjhositabbaṃ. esevanto rāgānusayānam, esevanto pațighānusayānạ̣, esevanto dițhānusayānạ̣ esevanto vicikicchānusayānaṃ, esevanto mānānusayānaṃ, esevanto bhavarāgānusayānaṃ, esevanto avijjānusayānaṃ, esevanto daṇ̣ādānasatthādāna-kalaha-viggaha-vivāda-tuvaṃtuvaṃ-pesuñña-musāvādānaṃ. etthete pāpakā akusalā dhammā aparisesā nirujjhantî̀' tì». 
«las percepciones sensoriales no hagan surgir las disposiciones latentes». El estado mental de una persona común, a diferencia del estado mental de un arahant, presenta como característica distintiva que las palabras que provienen de las percepciones sensoriales se multiplican, o se generan una y otra vez, y esta multiplicación de palabras, literalmente, fluye en su mente ${ }^{25}$. Esta sería la condición que explicaría por qué en la mente de una persona común las percepciones hacen surgir las tendencias subyacentes o disposiciones latentes, que son las responsables de que aparezcan los conflictos y disputas en el mundo. En el caso de la mente de la persona común, persisten además un número de tendencias subyacentes, una de las cuales está, en particular, relacionada con la aparición de las concepciones distorsionadas de la realidad (diț̣hānusayānam). Habría razones, en consecuencia, para entender la aparición de las concepciones distorsionadas de la realidad (dițhi) como el resultado de la continuada multiplicación de las palabras relacionadas con las percepciones sensoriales y de las provienen de la mente, que fluyen en la mente de una persona común.

Resumiendo, con la expresión «yatonidānam purisam papañcasañ̃̄āsañkhā samudācarantì, el Buddha explica dos características mentales: o la completa extinción de las tendencias subyacentes en la mente del arahant, o la persistente recurrencia de las tendencias subyacentes en la mente de la persona común. En uno y otro caso, la explicación del Buddha parece sugerir que en la mente de la persona corriente:

(i) las palabras que se utilizan para referirse a las percepciones sensoriales pueden intervenir en la aparición de los conflictos y disputas en el mundo,

(ii) que si las percepciones sensoriales tienen la capacidad de generar tendencias subyacentes en la mente de la persona común, debe de existir algún mecanismo mental que explique de qué manera las percepciones sensoriales generan tendencias subyacentes,

(iii) que papañca es el mecanismo mental que multiplica en la mente de la persona común las palabras relacionadas con las percepciones sensoriales,

(iv) en consecuencia ha de existir alguna relación entre papañca, las distinciones verbales que proceden de las percepciones sensoriales y la aparición de las tendencias subyacentes, y finalmente,

(v) que las concepciones distorsionadas que eventualmente expresan las proposiciones (1)-(10), estarían relacionadas con papañca, si es entendido como el mecanismo responsable de la generación de tendencias subyacentes que producen visiones distorsionadas (ditthi).

De acuerdo con Buddhaghosa ${ }^{26}$, para entender el significado de la expresión «papañca-sañ̃̄ā-sańkhā» («la generación mental (multiplicación) de las distinciones verbales que provienen de las percepciones»), es necesario identificarla como un compuesto de dos elementos: el primero es «papañca-sañ̃̄ā», y el segundo «san்khā»».

25 El verbo «samudācaranti» (sam, ud, ācarati), indica la acción de algo que está ocurriendo continuamente, de ahí la idea de fluir,

26 Papañcasūdanī, 75:

«yatonidānanti bhāvanapuṃsakaṃ etạ̣, yena kāraṇena yasmị̣ kāraṇe satīti attho. Papañcasaññāsan̉khāti ettha sańkhāti koțṭhāso». 
Por una parte, el significado de «papañca-sañ̃̃ā», Buddhaghosa lo explica en los siguientes términos:

«La multiplicación mental de las percepciones significa la multiplicación mental de (aquellas percepciones) de la avidez, de las que están relacionadas con la identidad personal y de las concepciones distorsionadas condicionadas por (el principio) de asociación, se las conoce bajo el nombre de «percepciones», o también bajo la denominación de «multiplicaciones mentales». Por esta razón, lo que se denomina «la multiplicación mental de las distinciones verbales»»» tiene ese significado. En cuanto al (verbo) «samudacaranti» significa «fluir» ${ }^{27}$.

Por otra parte, Buddhaghosa interpreta el sentido de la palabra «sańkhā» como kotthāso, que significa, entre otras cosas, «división», «parte» o «porción», a veces se emplea para dar entender también «participación». Buddhagosa parece sugerir con el uso del término «kotthāso», la habilidad que tiene el lenguaje de discriminar, o hacer distinciones, que presumiblemente impondría una manera distorsionada de entender la realidad, probablemente debido a la tentación de identificar erróneamente como «realidades últimas» distinciones convencionales que se hacen sólo en virtud de la estructura representativa del lenguaje sobre la que se construye la realidad convencional ( sammuti-saccā).

La expresión «papañca-sañ̃̄ā-san்khā» indicaría la continua generación mental, o la multiplicación de las distinciones verbales o convencionales que se hace en términos de la estructura simbólica y sintáctica del lenguaje, a partir de las percepciones sensoriales, que incluiría las percepciones que provienen de los cinco sentidos y las percepciones mentales. Estas distinciones se manifiestan en la conciencia como el resultado de la actividad de tres factores: la avidez (tanh â), la inclinación a concebir los fenómenos que se detectan en la conciencia como atributos de una entidad (yo) (māna), y como una distorsión conceptual (ditthi).

Buddhaghosa presenta la acción mental de papañca, es decir, de la continua generación mental o de la multiplicación de estructuras simbólicas, como una actividad que proyecta sobre la conciencia una realidad ilusoria o engañosa. De hecho, la multiplicación de todas las distinciones verbales con las que se expresan las percepciones son el resultado simplemente de la actividad de pensar, que se entiende esencialmente como la generación de continuos procesos mentales, cuyo origen, en los términos en los que entiende Buddhaghosa, consiste en la actividad generativa específica que desarrolla tạ̣hā, māna y diț̣hi respectivamente:

«El origen de la multiplicación de las distinciones verbales de las percepciones significa lo siguiente: las tres multiplicaciones mentales, la multiplicación mental de la avidez, la multiplicación mental de las ideas sobre la identidad personal, la multiplicación mental de las opiniones distorsionadas. Por esta razón, el conjunto de las ciento ocho diferentes clases de avidez se le llama «la multiplicación (generación) mental de la avidez». Las nueve clases de concepciones sobre la identidad personal (uno mismo) se llaman «la multiplicación mental (generación) de concepciones sobre

27 Puggalapañ̃̃atti, 75:

«Papañcasaññāti taṇhāmānadițthipapañcasampayuttā saññā, saññānāmena vā papañcāyeva vuttā. Tasmā papañcakoț̣̂āsāti ayamettha attho. Samudācarantīti pavattanti». 
la identidad personal». Las sesenta y dos clases diferentes de concepciones distorsionadas se llaman «la multiplicación (generación) mental de concepciones distorsionadas». En este caso (por esta razón), se refieren a ellas como la «la multiplicación (generación mental) de la avidez». ¿A dónde conduce la multiplicación (generación) mental? La multiplicación mental conduce a la intoxicación y a las acciones inmorales. En cuanto a las percepciones, las percepciones son multiplicadas por papañca. Las distinciones verbales se llaman «partes. «Las causas de las percepciones, de la multiplicación (generación) mental y de las distinciones verbales», son en cada una de las tres las mismas» ${ }^{28}$.

Parece claro que Buddhaghosa no está reclamando que tạ̣hā, māna y dițhi signifiquen lo mismo, sino, más bien, que las tres deberían de entenderse como el resultado de la misma actividad generativa de la mente (papañca). Los procesos cognitivos en cuyos términos la realidad convencional es conocida, son el resultado de la generación continua de patrones simbólicos de representación que Buddhaghosa identifica con la acción mental de papañca. La avidez (tanhā) es simplemente la proyección sobre la conciencia de un proceso generativo, que continuamente genera patrones simbólicos de representación conceptual (ditthi), probablemente basados en la tendencia generativa a conceptualizar la realidad como la acción de un sujeto que perpetúa el concepto de sí mismo (māna). Buddhaghosa también identifica la condición de asociación (sampayutta) como la responsable de que papañca multiplique o genere continuamente patrones de representaciones a partir de las distinciones verbales (conceptos) vinculadas a las percepciones sensoriales. Es posible que Buddhaghosa esté queriendo dar a entender:

(i) que la actividad de pensar es esencialmente una actividad generativa,

(ii) que aparece en la conciencia como la manifestación de la avidez, la construcción de la identidad personal, y las concepciones distorsionadas, $\mathrm{y}$

(iii) que como resultado de la intervención de esos tres factores, es una actividad que crea ilusión mental, y por consiguiente es esencialmente engañosa.

La referencia a taṇhā, māna y ditthi como las tres multiplicaciones mentales, podría arrojar alguna luz para entender los mecanismos psicológicos que intervienen en la formación de las tendencias subyacentes (anusaya $\vec{a}$ ), y eventualmente comprender las razones que podrían haber llevado al Buddha a calificar a los enunciados (1)-(10), como dițthigatametam, ditțhikantāro ditțivisūkam.

Papañca, como cualquier estado mental condicionado, también tiene sus consecuencias. Buddhaghosa utiliza la expresión «mattapamattākārapāpanațhena» para describir las consecuencias psicológicas resultantes de la acción de papañca. El término «mattapamattā» significa literalmente intoxicarse con sustancias tóxicas o venenosas, pero también se utiliza para indicar la acción de intoxicarse con la idea de uno

28 Sumañgalavilāsinī 721,12:

papañcasaññāsan̉khānidāno_ti tayo papañcā tạ̣hāpapañco, mānapapañco, ditṭhipapañcoti. tattha aț̣hasatatạ̣hāvicaritạ̣ tạ̣hāpapañco nāma. navavidho māno mānapapañco nāma. dvāsaț̣̂hi diț̣hiyo dițhipapañco nāma. tesu idha tạ̣hāpapañco adhippeto. kenaț̣hena papañco? mattapamattākārapāpanaț̣̂hena papañco. tamsampayuttā saññā papañcasañña. san̉khā vuccati koț̣̂hāso «saññānidānā hi papañcasan̉khā» tiādīsu viya 
mismo. Si se considera el primer significado, es posible que Buddhaghosa esté dando a entender que la generación de conceptos y distinciones verbales que provienen de las percepciones tienen el poder de intoxicar la mente. Debido a la naturaleza generativa de papañca la multiplicación continua de conceptos y concepciones distorsionadas perpetúan un estado mental nocivo cada vez que se repite o multiplica una determinada concepción.

Por otra parte, bajo la interpretación del segundo significado, Buddhaghosa esté identificando la tendencia generativa a preservar una cierta identidad personal, cuyos términos se refuerza la idea personal de uno mismo. En otro pasaje, Buddhaghosa resalta la acción psicológica de papañaca como «mattapamattākārabhāvena» ${ }^{29}$, es decir que tiene la capacidad de producir la ilusión mental comparable a la que aparece en un estado psicológico de «devaneo», «delirio», o «desvarío», que mantiene a los seres sumidos en la ignorancia que impide que se percaten que la actividad generativa de papañca los mantiene atados a las innumerables vueltas de la existencia.

Buddhaghosa finalmente considera las tendencias o disposiciones subyacentes (anusayâ) como engaños mentales o impurezas mentales (kilesa) ${ }^{30}$. Para entender las tendencias subyacentes como engaños mentales es preciso haber identificado a papañca como la actividad mental que genera continuamente patrones simbólicos de representación que intoxican la mente. La idea que el término «kilesa» parece convenir está relacionada, pues, con la habilidad generativa de papañca de crear una ilusión mental que literalmente «fuerza» a los seres a permanecer en una condiciones mentales sucias, manchadas o impuras ${ }^{31}$. En el Abhidhamma se consignan diez tipos de impurezas mentales, respectivamente: avidez (lobho), odio (doso), ilusión mental (moho), la importancia de la identidad personal (māno), concepciones distorsionadas (ditthi), incertidumbre (vicikicchā), pereza (thīnami), desasosiego, o intranquilidad mental (uddhaccanam), desvergüenza (ahirikam) y ausencia de remordimiento ante una acción inmoral (anottapami) ${ }^{32}$.

La naturaleza de la ilusión mental que produce las impurezas mentales (kilesas) $\mathrm{y}$, en particular, su perdurable influencia en la generación de patrones mentales distorsionados difícilmente se puede apreciar, a menos que se examine la relación entre las impurezas mentales (kilesas) y los efluvios mentales (āsavas) ${ }^{33}$. El término

29 Papañcasūdanī II 10,15:

«papañco ti ca mattapamattākārabhāvena pavattānam tạ̣hādiț̣imānānam etam adhivacanaṃ».

30 La evidencia para interpretar las impurezas mentales (kilesa) como los resultados de la acción generativa de papañca la proporciona Buddhaghosa en Paramathadīpani, 372.

31 El verbo «kilissati» en Pāli (del Sánscrito «klish», significa etimológicamente «pegar»o «adherirse», «fijar», «clavar») parece convenir la idea de «mancharse», «estar sucio, o mojado», o de estar en un estado de impureza mental que induce a cometer acciones inmorales. En ocasiones también se emplea para significar «afligir», «preocupar»o «perturbar».

32 Dhammasangan̄ī 215:

«katame dhammā kilesā? dasa kilesavatthūni - lobho, doso, moho, māno, diț̣hi, vicikicchā, thīnam, uddhaccam, ahirikam, anottappam̀».

33 Véase Paramathadīpani 372 y Paramathadīpani 373, 22. 
«āsava» significa literalmente «algo que fluye, o mana». En el Canon aparece asociado a dos sentidos, el primero lo ilustra las metáforas asociadas a la fermentación que se produce en la destilación de licores, sustancias tóxicas, cocciones y mucílagos ${ }^{34}$; el segundo con la exudación de pus que proviene de las llagas ${ }^{35}$. Los dos sentidos indican la idea de algo que se está fermentando durante un tiempo, que trastorna o distorsiona los sentidos, o que produce dolor. Se podría pensar en los āsavas como la emanación o la fermentación de los engaños o impurezas mentales (kilesa), el resultado de la acumulación de los efectos mentales de las tendencias subyacentes (anusayā) no sólo durante la presente existencia, sino como consecuencia de los efectos acumulativos de las existencias anteriores.

$\mathrm{Si}$ las tendencias subyacentes (anusayā) se entienden como los efectos subconscientes de la acción generativa mental de papañca asociada a la identidad personal y a la generación de patrones simbólicos de representación que distorsionan la realidad, los efluvios mentales (āsavā) serían meramente la fermentación mental de los efectos acumulativos que continuamente produce la acción de papañca en el ciclo de las existencias. Puesto que papañca, en el diagnóstico de Buddhaghosa, tiene la capacidad de intoxicar la mente, los efluvios mentales (āsavas) se podrían considerar como una fuerte inclinación mental a reproducir inconscientemente los patrones simbólicos de representación, una tendencia mental a percibir una y otra vez la realidad de la manera en que ha sido generada por papañca en las transcurso de las vueltas del samisāra y que es reforzada por la gratificación emocional de las conductas que surgen como consecuencia de la necesidad psicológica de satisfacer patrones específicos de apego.

En el Canon se encuentra dos clasificaciones de los efluvios mentales. En la primera se incluyen tres āsavas:

«En relación con esto, cuáles son los tres efluvios mentales? El efluvio del placer sensual, el de la existencia y el de la ignorancia.

Qué es el efluvio mental de los placeres sensuales? Aquello que [consiste] en gozar de los placeres sensuales, la [gratificación] de los deseos carnales, el gozo, las ganas, el deseo, la pasión [lo que consume], el encaprichamiento [la infatuación] y el apego por los placeres sensuales.

Qué es el efluvio de la existencia? Aquello que [consiste] en gozar de los placeres sensuales, la [gratificación] de los deseos carnales, el gozo, las ganas, el deseo, la pasión [lo que consume], el encaprichamiento [la infatuación] y el apego por las existencias.

Qué es el efluvio de la ignorancia? La ignorancia del sufrimiento [de lo que es intrínsecamente insatisfactorio]... la barrera de la ignorancia, la ilusión enraizada en

34 Especialmente en los siguientes pasajes:

Visuddhimagga, 445: «āpādhikassa āsavassa gandhato».

Kan̉khavitaran̄ī, 118: «pupphādihi kato āsavo merayaṃ».

Papañcasūdanī, I 61: «ciraparivāsikatțhena madirādayo āsava viyāti pi āsava».

Sāratthappakāsinī, III 303: «merayạ̣ nāma pupphāsavo phalāsavo ti evamuvutto yo koci āsavo».

35 Véase en particular: Puggalapaññatti, 30; Añguttara Nikāya i, 124 y Puggalapaññattiatthakathā, 212. 
las acciones inmorales — esto es lo que se conoce como «el efluvio de la ignorancia». Esos son los tres efluvios ${ }^{36}$.

Por su parte, la segunda clasificación añade simplemente las concepciones distorsionadas (ditthi) que expresan los enunciados (1)-(10) a la lista de efluvios mentales:

«Cuál es el efluvio de las concepciones distorsionadas? «El universo es eterno», «el universo no es eterno», «el universo es finito», «el universo no es finito», «el alma y el cuerpo son lo mismo», «el alma es una cosa y el cuerpo otra», «el Tathāgata existe después de la muerte», «el Tathāgata no existe después de la muerte», «el Tathāgata existe y no existe después de la muerte», «el Tathāgata ni existe y ni deja de existir después de la muerte». Tale son los efluvios de las concepciones distorsionadas, la espesura de las opiniones distorsionadas ... etc ... el apegarse a las concepciones distorsionadas- esto se conoce como «el efluvio de las concepciones distorsionadas». Todas las concepciones falsas son efluvios de concepciones distorsionadas $\rangle^{37}$.

Identificar la ignorancia como un efluvio mental indica que, una vez que es creada por la acción de papañca, los diferentes patrones de representación distorsionada de la realidad tienden a manifestarse como una tendencia subyacente que obstaculiza la mente a acceder al conocimiento de las cuatro verdades nobles, como se reconoce en el Abhidhamma:

«Qué es el efluvio de la ignorancia? La ignorancia del sufrimiento, la ignorancia del origen del sufrimiento, la ignorancia de la cesación del sufrimiento, la ignorancia del camino que conduce a la cesación del sufrimiento, la ignorancia de las existencias pasadas, la ignorancia de las existencias por venir, la ignorancia de las existencias pasadas y futuras, la ignorancia de que todos los sucesos tienen como fundamento el principio según el cual todo lo que surge depende de una condición: la ausencia de ser consciente, de comprensión, de realización, de despertar, de inmersión, de penetración, de sumersión, de visión, de contemplación, de percepción directa; una necedad, una estupidez, sin la completa comprensión, engañoso, desconcertante, lleno de ilusión, (basado) en la ignorancia, atrapado en la corriente de la ignorancia, sujeto a

\section{Vibhanga, 364:}

tattha katame tayo āsavā? kāmāsavo, bhavāsavo, avijjāsavo.

tattha katamo kāmāsavo? yo kāmesu kāmacchando kāmarāgo kāmanandī kāmatanhhā kāmasineho kāmaparị̣āho kāmamucchā kāmajjhosānạ̣ — ayạ̣ vuccati «kāmāsavo».

tattha katamo bhavāsavo? yo bhavesu bhavacchando ... pe ... bhavajjhosānam — ayạ̣ vuccati «bhavāsavo».

tattha katamo avijjāsavo? dukkhe aññānamạ ... pe ... avijjālanigī moho akusalamūlaṃ - ayạ̣ vuccati «avijjāsavo». ime tayo āsavā.

37 Vibhanga, 374:

«tattha katamo ditțhāsavo? «sassato loko» ti vā, «asassato loko» ti vā, «antavā loko» ti vā, «anantavā loko» ti vā, «tạ̣ jīvaṃ tạ̣ sarīra» ti vā, «aññam jīvaṃ aññam sarīra» ti vā, «hoti tathāgato paraṃ maraṇā» ti vā, «na hoti tathāgato paraṃ maraṇā» ti vā, «hoti ca na ca hoti tathāgato param maraṇā» ti vā, «neva hoti na na hoti tathāgato param maraṇā» ti vā. yā evarūpā diț̣hi diț̣igatạ̣ ... pe ... vipariyāsaggāho — ayạ̣ vuccati «diț̣āsavo». sabbāpi micchādiț̣i diț̣hāsavo». 
la ignorancia, (intoxicado) por las disposiciones latentes de la mente de la ignorancia, dominado por la ignorancia, entorpecido por la ignorancia, ofuscado por la raíz de la conducta inmoral» ${ }^{38}$.

Como un efluvio (avijjāsavo), la ignorancia proporciona una idea precisa sobre la naturaleza de los obstáculos mentales que crean los efectos de papañca a lo largo de las vueltas del samisāra. La secuencia de frases compuestas de conceptos y distinciones verbales que genera los patrones lingüísticos de representación, son estados mentales condicionados generados por la actividad de papañca vinculada a la construcción subjetiva de la identidad personal (māna). La mente es condicionada a seguir una secuencia de conceptos de acuerdo a un particular gramática que incesantemente proyecta sobre la conciencia representaciones subjetivas de la realidad, bajo la ilusión de que las ideas que se expresan en el lenguaje reflejan cómo es en efecto la realidad (yathābuthānami). Esta ilusión se mantiene a los largo de las vueltas de las existencia como consecuencia de la acción de los efluvios, y tiene dos consecuencias inmediatas. En primer lugar perpetúa en la conciencia la imposibilidad epistemológica de acceder al conocimiento de las cuatro verdades nobles; y en segundo lugar, previene que la mente llegue a ver la ocurrencia de todos los fenómenos como estados condicionados sujetos al principio de condicionalidad.

Que cada una de las proposiciones contenidas en la lista (1)-(10) sea entendida como un efluvio mental significa reconocer cada proposición como el resultado de la fermentación de la incesante actividad mental de papañca a lo largo de las vueltas del samisāra. Como efluvios mentales (āsava), son el resultado acumulativo de la acción de tạnhā, sañ̃̄ā, māna, upādāna, y en último extremo de la acción generativa de patrones mentales de representación activada por papañca ${ }^{39}$. Cada una de ellas representa un capa de distorsión conceptual que ha sido reforzada en cada existencia por esquemas de apego que probablemente contribuyan a reforzar la identidad personal. Estos esquema de apego proporcionan la base emotiva para sustentar diferentes patrones subjetivos de concepciones distorsionadas, que a través de la repetición, perpetúan como fermentos una forma particular de ignorancia con cada nueva existencia.

De hecho, entender las proposiciones (1)-(10) como fermentos o efluvios mentales nos da una idea bastante aproximada de la insuperable dificultad psicológica que supone removerlas de la conciencia y eventualmente arroja alguna luz para entender lo que el Buddha pudo haber querido decir cuando se refería a las proposiciones (1)-(10) como dițthigatametam, dițthikantāro y dițhivisūkam. El alcance del obstáculo psicológico que representa respectivamente los términos gatametam, kantāro y visūkaṃ cuando se aplican a las concepciones distorsionadas se basa en particular en:

38 Dhammasañgan̄ī 196:

tattha katamo avijjāsavo? dukkhe aññānam, dukkhasamudaye aññāṇạ̣, dukkhanirodhe aññānạ̣, dukkhanirodhagāminiyā paṭipadāya añ̃nāṇam, pubbante aññānạ̣, aparante aññānaṃ, pubbantāparante aññạnam, idappaccayatā paticcasamuppannesu dhammesu aññānam: yam evarūpam aññạ̄am adassanaṃ anabhisamayo ananubodho asambodho appaṭivedho asamgāhanā apariyogāhanā asamapekkhanā apaccavekkhạ̣ā apaccakkhakammạ̣ dummejjhạ̣ bālyạ̣ asampajaññạ̣ moho pamoho sammoho avijjā avijjogho avijjāyogo avijjānusayo avijjāpariyutṭhānam avijjālañgī moho akusalamūlam — ayạ̣ vuccati avijjāsavo

39 Anguttara Nikāya iv, 69. 
(i) la actividad generativa de papañca como responsable de la generación de patrones simbólicos de representación basados en las distinciones conceptuales del lenguaje ( papañca-sañ̃̄a-sankkhā),

(ii) en la función que desempeña la construcción de la identidad personal (māna) en la generación de patrones de representación,

(iii) en la repetición de patrones distorsionados de representación causada por la actividad, en gran parte inconsciente, de las tendencias subyacentes (anusayā),

(iv) en la intoxicación mental que produce la repetición inconsciente de las concepciones distorsionadas (kilesa),

(v) en la persistencia de la acción inconsciente de las tendencias subyacentes que como fermentos mentales (āsava) condicionan la aparición de patrones de ignorancia en futuras existencias.

La presencia de los anteriores elementos incluidos en (i)-(v) hace que cualquier intento de argumentación racional sea ineficaz para desactivar la persistente generación de patrones de concepciones que papañca ha venido creando en el curso de los ciclos de existencia. Los términos «gatametam!», «kantāro» y «visūkaṃ» que el Buddha emplea para calificar a las concepciones distorsionadas como «espesura mental», «jungla o maraña» y «retorcimiento» podrían entenderse en términos de los efectos acumulativos que resultan

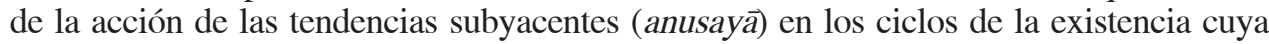
persistencia perpetúa la ignorancia induciendo a la mente a repetir una y otra vez los patrones mentales de representación a través de la acción de los efluvios mentales (āsava).

El problema no puede resolverse en términos del principio de no contradicción, porque la cuestión no es de consistencia lógica; sino de la naturaleza misma de la concepción y de la generación de patrones de representación conceptual. Entender las proposiciones (1)-(10) como una espesura o una jungla o un retorcimiento de concepciones distorsionadas implica cuestionar la generación de patrones de representación como una distorsión de la realidad; y la dificultad mental no puede eliminarse sustituyendo una concepción por otra, sino rechazando la actividad de pensar como la raíz misma de donde surge la ilusión mental, que nos obliga a creer que la realidad es como es concebida por la actividad de pensar.

Como efluvios mentales, las proposiciones (1)-(10) son el resultado de la fermentación de estructuras mentales vinculadas a esquemas de apego emocional que refuerzan la identidad personal. La actividad de māna consiste en la construcción de la identidad personal generando tres concepciones distintivas del sujeto relacionadas entre sí, a partir de la distorsión conceptual que ejercen en la conciencia las ideas sobre la identidad personal. Estas son las responsables de registrar los procesos continuos de la percepción sensorial y mental como si fueran acciones realizadas por un sujeto o un yo. La primera se basa en la creencia de que existe una esencia o substancia que subyace como sujeto de los procesos mentales ( sārakattena-attā); la segunda que el yo se considera como el poseedor de los procesos mentales que ocurren en la conciencia, o que la conciencia pertenece al sujeto ( sāmikatthena-attâa); y la tercera que el yo parece dotado del poder de dirigir el comportamiento (vasavattanatthena-attāa ${ }^{40}$.

40 Sigo la explicación del Ven. Ledi Sayadow, «The Sammādiț̣i Dīpanī», The manuals of Dhamma, trad. de Sayadaw U Nyana y otros, Vipassana Research Publications, Onalaska, WA, 2016, 109-10. 
En esencia, la construcción subjetiva de la identidad personal basada en las idea pictóricas de continuidad es uno de los factores responsables del apego asociado a las concepciones distorsionadas. Probablemente la idea que se encuentre detrás es que no sólo pensamos para concebir la realidad, sino que pensamos para identificarnos con las creencias que sostenemos sobre la realidad que asumimos saber. Los términos «gahanam» (apegarse), «vipphanditam» (crisparse) aplicados a las concepciones distorsionadas (ditthi) estarían relacionados con las vinculaciones emocionales que produce la identificación subjetiva de las creencias que se defienden como si fueran nuestras, o nos identificaran de alguna manera; mientras que el término «saṃyojanaṃ» (atadura) haría referencia la dificultad acumulada que produce la persistencia de la ignorancia en el transcurso de los ciclos de la existencia.

Al contrario de lo que implica la línea de la interpretación que insiste en que el Buddha podría haber respondido las preguntas que deja indeterminadas, existe una conexión lógica entre las dos clases de razones que da el Buddha para explicar su silencio. La razón para rechazar los enunciados (1)-(10) porque conducen:

«al sufrimiento, a lo que causa irritación, a la aflicción, a la excitación (fiebre); no conducen a la disipación de la ilusión [mental], ni a la serenidad, ni a la cesación, ni a la paz, ni al conocimiento intuitivo, ni al despertarse por uno mismo, ni tampoco al nibbānamì

se basa precisamente en que sean percibidos como la manifestación de una prolongada ignorancia. En consecuencia, sostener que los enunciados (1)-(10) expresen manifestaciones distorsionadas (ditthi) y puedan ser decidibles, pero que el Buddha no estaba interesados en ellos, es contradictorio con el hecho de que han sido declarados por el Buddha como ditthi. Las concepciones distorsionadas no pueden estar sujetas a criterio alguno de decibilidad semántica, porque la creencia sobre la que se justifica su sentido es una ilusión mental. La disipación de esta ilusión requiere la extinción de los mecanismos cognitivos que genera papañca.

El silencio del Buddha se basa en el diagnóstico de que el estado mental de aquél que formula las preguntas (1)-(10) es el resultado de una prolongada intoxicación conceptual y que, como consecuencia de esta intoxicación, la persona que las formula no se encuentra en la disposición mental adecuada para percatarse que lo que está preguntando es el reflejo de una prolongada ilusión mental. La terapia no funciona si se refuerza la ilusión discutiendo, argumentando, o declarando que los enunciados (1)-(10) son simplemente absurdos. La naturaleza de la ilusión mental impide que la persona que se encuentra bajos los efectos de una intoxicación conceptual se percate de que lo que está preguntando es meramente el producto de una ilusión que ha creado la actividad de papañca.

Visto así, parece que el silencio del Buddha ante las preguntas (1)-(10) tiene una profunda significación terapéutica. Cualquier declaración orientada a esclarecer el sentido de las proposiciones (1)-(10), cualquier argumento concebido para remover su intrincada espesura conceptual, toda discusión filosófica sobre la imposibilidad de llegar a saber lo que cada uno de los enunciados se propone averiguar, no haría más que aumentar la distorsión conceptual y reforzar los patrones de apegos de identificación subjetiva; lo que presumiblemente conduciría a nuevos conflictos, enfrentamientos y disputas, que son visiblemente inconsistentes con el conjunto de principios que el mismo Buddha ha declarado de manera explícita. 
El silencio también se podría considerar como un prueba del estado mental al que llega un arahant, que contrasta con la disipación conceptual de la persona común. Estrictamente hablando, la mente de un arahant no tiene la capacidad de generar la clase de estructuras conceptuales que le permita concebir la formulación linguística de las preguntas (1)-(10). La completa extinción de las tendencias subyacente hace que esa capacidad no pueda activarse y le impida tener acceso al contenido conceptual en cuyos términos se formula cada una de las preguntas. Esto no significa que no pueda entender de lo que se está preguntando, sino simplemente que las estructuras conceptuales de comprensión mental han sido desactivadas. La mente del arahant ha alcanzado el poder de erradicar la generación de estructuras conceptuales de la misma manera en que un hombre cuyas manos y pies han sido cortados es capaz de pensar y de saber que no tiene esos miembros ${ }^{41}$.

El estado mental de un arahant sólo puede lograrse por medio de la completa extinción de los efluvios mentales (āsavā), cuando la capacidad mental de papañca de generar conceptos y patrones de representación se ha extinguido enteramente. En realidad, no es posible saber qué es lo que significa saber utilizar los conceptos como si se hubieran extinguidos, fuera del estado mental del arahant. Sea lo que fuera lo que signifique, debería de considerarse como una condición epistemológica necesaria para evaluar la ineficacia epistemológica de comprender la realidad última en términos de la construcción mental de la realidad que hace papañca. En cualquier caso, parece que esta condición es lo que eventualmente nos permitiría entender las razones del silencio del Buddha, lo que implicaría tener al acceso al estado mental del arahant, que sería inaccesible para aquellos que no han alcanzado la completa iluminación. De hecho, en términos psicológicos, el silencio del Buddha sería sólo comprensible para aquellos que han extinguido por completo la actividad de papañca en su mente y han cortado de raíz la acción inconsciente de las tendencias subyacentes (anusayâ) y de los efluvios mentales (āsava).

En último extremo, el imperturbable silencio del Buddha antes las preguntas (1)-(10) revela el desconcertante desafío epistemológico que el budismo presenta a uno de los presupuestos básicos de la filosofía occidental: que la comprensión de la realidad depende necesariamente de que sea conceptualizada por las estructuras mentales que forman parte del lenguaje en cuyos términos se explica el sentido de los fenómenos que se conciben. Todas las reivindicaciones epistemológicas sobre el alcance de lo que se considera conocido resulta ser asunciones relativas a un conjunto de estructuras conceptuales que tienen el poder de concebir mentalmente la realidad y en cuyos términos se justifican la verdad del conocimiento. Lo que el Buddha está desafiando es que lo que consideramos como el conocimiento de la realidad es en último extremo la manifestación de una ilusión mental que, cuando es pensada una y otra vez por los patrones de subjetivos de representación asociados a la actividad de papañca, paradójicamente se convierte en un obstáculo que esconde detrás de nuestras concepciones la realidad tal y como es (yathābuthānami). La realidad, parece ser la conclusión, no se comprende, más bien se penetra, y penetrarla significa borrar la línea que separa el sujeto del mundo que comprende.

41 Para una descripción más precisa del estado mental del arahant véase Majjhima Nikāya i, 523. 
BiBLIOGRAFÍA

Fuentes primarias ${ }^{42}$

Anuruddha, Ācariya. (1999). Abhidhammatthasangaha. A Comprehensive Manual of Abhidham$m a$, edi-tado por Bhikkhu Bodhi. Kandy: Buddhist Publication Society.

Añguttara Nikāya

Dhammasangan̄ī,

Dīgha Nikāya

Majjhima Nikāya

Papañcasūdanī

Paramathadīpani

Puggalapaññatti

Samyutta Nikāya

Sāratthappakāsinī,

Sumañgalavilāsinī

Vibhanga

Vinayapitakam

Visuddhimagga

\section{Fuentes secundarias}

Gethin, R. (1998). The foundations of Buddhism. Oxford: University Press.

Norman, K. R. (1991). «Death and the Tathāgata», en Studies in Buddhism and Culture (in honour of Prof. Egaku Mayeda), Tokyo, pp. 252-63.

Panikar, R. (1996). Los silencios del Buddha. Madrid: Siruela

Sayadow, L. (2016). The manuals of Dhamma. Onalaska, WA: Vipassana Research Publications. Vetter, T. (1988). The ideas and meditative practices of Early Buddhism. E. J. Brill: Leiden.

Universidad de Sevilla. Facultad de Filosofía

ENRIQUE BOCARDO

Visiting Scholar, Wolfson College (Cambridge)

Email: bocardo@us.es

[Artículo aprobado para publicación en enero de 2018]

[NOTA DE LA REDACCIÓN: la transcripción de los textos de la tradición budista, escritos en pali, desde el documento proporcionado por el autor al texto formateado en la imprenta, no ha sido fácil, con las aplicaciones disponibles. Dado el interés del artículo, hemos considerado publicar el artículo a pesar de los errores de la transcripción, de los que en ningún caso es responsable el autor del artículo].

42 Todas las citas de los textos del Pāli Canon, salvo indicación previa, se refieren a la edición del Sexto Concilio Budhista (CSCD) 